
Motrivivência
v. 26,
n. 42 ,
p. 194-206, junho/2014

\title{
A PESQUISA ACADÊMICA SOBRE A INSERÇÃO DA DIMENSÃO AMBIENTAL NA EDUCAÇÃO FÍSICA NO BRASIL
}

Cae Rodrigues

RESUMO

O objetivo da pesquisa apresentada se desenvolve em torno da questão: considerando a dimensão global do "acontecimento ambiental" e a tendência à ambientalização das diferentes áreas do conhecimento, quais são os desenvolvimentos desses processos no campo da educação física no âmbito da pesquisa acadêmica? O corpus da pesquisa foi composto por discursos publicados em periódicos científicos que apresentam propostas de inserção da dimensão ambiental na educação física no Brasil. O corpus foi analisado a partir da Análise Textual Discursiva e os resultados evidenciam tendências e questões que se desdobram sobre processos de ambientalização da educação física no Brasil na atualidade.

Palavras-chave: Meio Ambiente; Gestão do Conhecimento; Educação. 


\section{INTRODUÇÃO}

Levando em consideração as disputas que se desdobram em meio à reprodução (e consequente perpetuação) de símbolos legitimados/naturalizados como dominantes por históricos embates de força e a construção/legitimação de novos/diferentes símbolos que desafiam o convencionalismo do campo educativo, a pesquisa acadêmica se apresenta como significativo capital simbólico "formalizado" sustentado pela força do campo científico/acadêmico, uma vez que é no âmbito da pesquisa que a "comunidade acadêmica" reconhece e legitima os símbolos que de forma contínua e constante (re)constituem as "fronteiras" (alcances e limites) dos fenômenos socioculturais. Em outras palavras, reconhecendo-se o papel das instituições acadêmicas na legitimação de fenômenos socioculturais diante da sociedade de maneira mais ampla, a pesquisa desempenha um papel protagonista no reconhecimento/legitimação dos símbolos/ estruturas que constituem esses fenômenos, especialmente pelos próprios atores que fazem parte do universo acadêmico. Nesse contexto, os periódicos científicos aparecem como um dos principais instrumentos de reconhecimento/legitimação da pesquisa, uma vez que os discursos publicados em periódicos passam pela avaliação de atores que são reconhecidos diante da comunidade acadêmica como "especialistas", ou seja, atores da esfera dominante em suas áreas.
Nesses contínuos e constantes processos de construção/constituição dos fenômenos socioculturais no âmbito da pesquisa, as diferentes áreas do conhecimento disputam os espaços de apropriação da razão ou espaços de dominância, uma busca incessante por um "reconhecimento de autoria" sobre os símbolos em disputa (BOURDIEU, 2004). Nesse sentido, os símbolos e estruturas que constituem os saberes/conhecimentos associados a fenômenos socioculturais se diferenciam na medida em que se relacionam com o objeto e campo temático de cada ciência, o que não significa que se constituem, dessa maneira, novos campos de conhecimento, mas um saber que compreende abordagens epistemológicas e metodológicas que permitam abordar suas problemáticas diferenciadas ligadas a distintas formas de conhecimento. Isso é exatamente o que acontece, por exemplo, na constituição do saber ambiental (LEFF, 1997): como saber interdisciplinar apresenta desafios às diferentes disciplinas, considerando que a integração do saber ambiental não se faz simplesmente na seleção de elementos culturais potencialmente "ambientalizadores", mas nas problematizações que envolvem todo o desenvolvimento do conhecimento objetivando a criação de espaços interdisciplinares que legitimem o saber ambiental (LEFF, 1997).

No entanto, a institucionalização ${ }^{3}$ da problemática socioambiental constitui um processo bem recente e se desenvolve

2 O presente trabalho foi realizado com apoio do CNPq, Conselho Nacional de Desenvolvimento Científico e Tecnológico - Brasil.

3 Por institucionalização compreende-se o processo pelo qual uma sociedade desenvolve suas próprias estruturas de funcionamento. 
de maneira bem diferente nos diversos campos disciplinares (BURSZTYN, 2004). Estabelecendo vínculos com os campos de produção cultural relacionados a diferentes áreas disciplinares e científicas, os conhecimentos, valores e sensibilidades ambientais são produzidos e modelados pelas diferentes histórias, concepções, métodos e formas de organização de cada área específica (FARIAS, 2008). Pois é essa argumentação que fundamenta a questão central da pesquisa apresentada nesse artigo: considerando a dimensão global do acontecimento ambiental e a consequente tendência à ambientalização das diferentes áreas do conhecimento, quais são os desenvolvimentos particulares desses processos no campo da educação física no âmbito da pesquisa acadêmica?

Os dados coletados para a análise dos processos de ambientalização da educação física no âmbito da pesquisa são procedentes de discursos publicados em periódicos científicos, compreendendo que esses discursos possuem um prestígio especial uma vez que são submetidos à avaliação de atores que são reconhecidos/ legitimados como "especialistas" em suas áreas, consequentemente o legitimando como "significativo" para o desenvolvimento da área. Os seguintes critérios foram usados para a seleção dos periódicos que fizeram parte da pesquisa: (a) são reconhecidos nacionalmente como veículos de divulgação científica na área de educação física, estando listados no Sistema Integrado da CAPES na Área de Avaliação "Educação Física" ou "Interdisciplinar"; (b) possuem banco de dados digitalizado de livre acesso com possibilidade de pesquisa computadorizada por palavra chave; (c) apresentam uma descrição de "foco e escopo" com abertura para a possível publicação de artigos com ênfase em educação física, meio ambiente e educação ambiental. Durante o processo de seleção dos periódicos a primeira palavra-chave utilizada na pesquisa foi "Educação Física". Os periódicos que não apresentaram nenhum resultado para essa palavra-chave foram automaticamente excluídos da pesquisa. Não definimos, a priori, um espaço temporal para a seleção dos artigos. Esse espaço foi definido em cada periódico pela disponibilização de seu banco de dados digitalizado.

Seguindo esses critérios, a seguinte lista de periódicos foi elaborada: 
V. $26, \mathrm{n}^{\circ} 42$, junho/2014

Quadro 1: Periódicos pesquisados na busca por artigos que apresentam propostas de inserção da dimensão ambiental na educação física.

\begin{tabular}{|l|c|}
\hline Título do Periódico & ISSN do Periódico \\
\hline Acta do Movimento Humano & $1808-0987$ \\
\hline Ágora para la Educación Física y el Deporte & $1578-2174$ \\
\hline Arquivos em Movimento & $1809-9556$ \\
\hline Caderno de Educação Física: Estudos e Reflexões & $1676-2533$ \\
\hline Cadernos CEDES & $0101-3262$ \\
\hline Cadernos de Pesquisa & $0100-1574$ \\
\hline Conexões & $1983-9030$ \\
\hline Educação e Realidade & $0100-3143$ \\
\hline Educação Física em Revista & $1983-6643$ \\
\hline Inter-ação & $0101-7136$ \\
\hline Interface & $1807-5762$ \\
\hline Lecturas Educación Física y Deportes & $1514-3465$ \\
\hline Motrivivência & $2175-8042$ \\
\hline Motriz : Revista de Educação Física & $1980-6574$ \\
\hline Movimento \& Percepção & $1677-7360$ \\
\hline Movimento & $1982-8918$ \\
\hline Pensar a Prática & $1980-6183$ \\
\hline Revista Brasileira de Ciência e Movimento & $0103-1716$ \\
\hline Revista Brasileira de Ciências do Esporte & $0101-3289$ \\
\hline Revista Brasileira de Docência, Ensino e Pesquisa em & $2175-8093$ \\
\hline Educação Física & $1807-5509$ \\
\hline Revista Brasileira de Educação Física e Esporte & $1983-3083$ \\
\hline Revista da Educação física & $1517-1256$ \\
\hline Revista Eletrônica do Mestrado em Educação Ambiental & $2176-9443$ \\
\hline Revista Eletrônica Fafit/Facic & $1980-6892$ \\
\hline Revista Mackenzie de Educação Física e Esporte & $1679-8775$ \\
\hline Revista Sul-Americana de Filosofia e Educação & $1982-0305$ \\
\hline Revista Teias & $0256-6419$ \\
\hline FIEP Bulletin On-line & \\
\hline Fona AUTOR,2013 & \\
\hline
\end{tabular}

Fonte: $A \cup T O R, 2013$.

Uma vez selecionados os periódicos de acordo com os critérios adotados para a pesquisa, foram realizadas buscas nos bancos de dados digitais de cada periódico utilizando a palavra chave "Educação Física" em combinação com as palavras-chave "Meio Ambiente", "Ambiental", "Ambientalização", "Natureza", "Sustentabilidade" e "Desenvolvimento Sustentável". Apesar do reconhecimento de que os critérios adotados para a pesquisa possibilitaram uma representativa amostra de produções sobre o tópico analisado é necessário também reconhecer que a amostra resultante dificilmente contempla a totalidade dessas 
produções ${ }^{4}$. Os resultados são apresentados no quadro a seguir pela ordem em que os artigos foram encontrados nos respectivos periódicos, ou seja, seguindo a organização do Sistema Integrado da CAPES, que apresenta os periódicos em ordem alfabética:

Quadro 2: Produções científicas que apresentam propostas de inserção da dimensão ambiental na educação física no Brasil

\begin{tabular}{|c|c|c|c|c|}
\hline & Título do artigo & Autor(es) & Periódico & $\begin{array}{c}\text { Ano de } \\
\text { Publicação }\end{array}$ \\
\hline Texto 1 & $\begin{array}{l}\text { A Educação Ambiental na formação } \\
\text { de professores de Educação Física: } \\
\text { uma emergente conexão }\end{array}$ & Franscisco J. P. TAVARES & $\begin{array}{l}\text { Lecturas Educación } \\
\text { Física y Deportes }\end{array}$ & 2003 \\
\hline Texto 2 & $\begin{array}{l}\text { A Educação Ambiental no contexto } \\
\text { da Educação Física Escolar }\end{array}$ & $\begin{array}{l}\text { José E. N. VARGAS; } \\
\text { Francisco J. P. TAVARES }\end{array}$ & $\begin{array}{l}\text { Lecturas Educación } \\
\text { Física y Deportes } \\
\end{array}$ & 2004 \\
\hline Texto 3 & $\begin{array}{l}\text { Educação Física escolar e meio } \\
\text { ambiente: reflexões e aplicações } \\
\text { pedagógicas }\end{array}$ & $\begin{array}{l}\text { Luiz H. RODRIGUES; } \\
\text { Suraya C. DARIDO }\end{array}$ & $\begin{array}{l}\text { Lecturas Educación } \\
\text { Física y Deportes }\end{array}$ & 2006 \\
\hline Texto 4 & $\begin{array}{l}\text { Educação física, esporte e lazer na } \\
\text { natureza: preservação, modismo, } \\
\text { apologia. Será tudo isso? }\end{array}$ & $\begin{array}{l}\text { Disalda M. T. LEITE; } \\
\text { Carlos A. CAETANO }\end{array}$ & Motrivivência & 2004 \\
\hline Texto 5 & $\begin{array}{l}\text { A Educação Física frente a temá- } \\
\text { tica ambiental: alguns elementos } \\
\text { teórico-metodológicos }\end{array}$ & $\begin{array}{l}\text { Fabiano W. SILVA; } \\
\text { Ana M. SILVA; } \\
\text { Humberto L. D. INÁCIO }\end{array}$ & Motrivivência & 2008 \\
\hline Texto 6 & $\begin{array}{l}\text { Educação física na década da } \\
\text { educação para o desenvolvimento } \\
\text { sustentável }\end{array}$ & $\begin{array}{l}\text { Renata OSBORNE; } \\
\text { Washington A. BATISTA }\end{array}$ & Motriz & 2010 \\
\hline Texto 7 & $\begin{array}{l}\text { Cultura de movimento: reflexões } \\
\text { a partir da relação entre corpo, } \\
\text { natureza e cultura }\end{array}$ & $\begin{array}{l}\text { Marina I. B. S. MENDES; } \\
\text { Terezinha P. NÓBREGA }\end{array}$ & Pensar a Prática & 2009 \\
\hline Texto 8 & $\begin{array}{l}\text { Prática pedagógica em educação } \\
\text { física e a educação ambiental }\end{array}$ & $\begin{array}{l}\text { Maristela S. SOUZA; } \\
\text { Giane S. LARA }\end{array}$ & Pensar a Prática & 2011 \\
\hline Texto 9 & $\begin{array}{l}\text { Educação física, esporte e desenvol- } \\
\text { vimento sustentável }\end{array}$ & $\begin{array}{l}\text { Renata OSBORNE; } \\
\text { Carlos A. F. da SILVA; } \\
\text { Sebastião J. VOTRE } \\
\end{array}$ & Pensar a Prática & 2011 \\
\hline Texto 10 & $\begin{array}{l}\text { Educação física no ensino médio e } \\
\text { as discussões sobre meio ambiente: } \\
\text { um encontro necessário }\end{array}$ & $\begin{array}{l}\text { Simone M. GUIMARÃES e } \\
\text { colaboradores }\end{array}$ & $\begin{array}{l}\text { Revista Brasileira de } \\
\text { Ciências do Esporte }\end{array}$ & 2007 \\
\hline Texto 11 & $\begin{array}{l}\text { Educação física, meio ambiente } \\
\text { e aventura: um percurso por vias } \\
\text { instigantes }\end{array}$ & $\begin{array}{l}\text { Alcyane MARINHO; } \\
\text { Humberto L. D. INÁCIO }\end{array}$ & $\begin{array}{l}\text { Revista Brasileira de } \\
\text { Ciências do Esporte }\end{array}$ & 2007 \\
\hline Texto 12 & $\begin{array}{l}\text { Educação ambiental e educação fí- } \\
\text { sica: possibilidades para a formação } \\
\text { de professores }\end{array}$ & $\begin{array}{l}\text { Soraya C. DOMINGUES; } \\
\text { Elenor KUNZ; } \\
\text { Lísia C. G. de ARAÚJO } \\
\end{array}$ & $\begin{array}{l}\text { Revista Brasileira de } \\
\text { Ciências do Esporte }\end{array}$ & 2011 \\
\hline Texto 13 & $\begin{array}{l}\text { Implementação da educação am- } \\
\text { biental na graduação de professores } \\
\text { de educação física: uma reflexão }\end{array}$ & $\begin{array}{l}\text { Francisco J. P. TAVARES; } \\
\text { Maria I. C. LEVY }\end{array}$ & $\begin{array}{l}\text { Revista Eletrônica do } \\
\text { Mestrado em Educa- } \\
\text { ção Ambiental }\end{array}$ & 2001 \\
\hline
\end{tabular}

Fonte: $A \cup T O R, 2013$.

4 Osborne e col. (2011b) também apresentam uma análise de artigos sobre meio ambiente e sustentabilidade publicados em periódicos nacionais de educação física. Apesar da não concordância com alguns critérios de seleção adotados nos procedimentos de coleta de dados da referida pesquisa, reconhece-se que o artigo apresenta alguns interessantes dados quantitativos sobre a evolução da temática em periódicos nacionais. 
Os artigos encontrados a partir dos critérios adotados para a pesquisa formam o corpus para a análise sobre a inserção da dimensão ambiental na educação física no âmbito da pesquisa ${ }^{5}$. Seguindo a proposta de Análise Textual Discursiva (MORAES, 2003), metodologia escolhida para a análise dos dados dessa pesquisa, uma vez selecionado o corpus cabe ao investigador a desconstrução e unitarização do corpus, essencialmente um processo de desmontagem dos textos destacando elementos constituintes do corpus em busca de sentidos e relações com o foco principal da investigação. Após o processo de desmontagem dos textos, ou unitarização, a segunda fase ou segundo ciclo da Análise Textual Discursiva é realizada pelo estabelecimento de relações, ou categorização, e implica em construir relações entre as unidades de base combinando-as e classificando-as no sentido de compreender como esses elementos unitários podem ser reunidos na formação de conjuntos mais complexos (MORAES, 2003). Assim, a categorização das unidades de significado representa um processo de comparação constante entre as unidades em busca de agrupamentos de elementos semelhantes em função de um sentido pertinente aos propósitos da pesquisa.

Na presente pesquisa essa categorização foi definida a partir de "categorias emergentes" por um processo "interpretativo", ou seja, a partir da construção "[...] com base nos conhecimentos tácitos do pesquisador, sempre em consonância com os objetivos da pesquisa" (MORAES, 2003, p.195). Assim, centrado no objetivo de identificar as características particulares que se originam/ desenvolvem na intersecção entre o campo ambiental e da educação física no âmbito da pesquisa no Brasil, foram definidas três categorias que "sintetizam" as principais ideias apresentadas nos textos analisados: (a) educação ambiental pelo jogo/esporte e pelo lazer; (b) um "corpo" que é intermédio de uma visão sistêmica/não fragmentária; (c) a educação ambiental na educação física escolar. Como seria impossível a apresentação de cada uma das categorias considerando o limite de caracteres atribuídos a presente forma de publicação ${ }^{6}$, serão apresentadas na próxima parte do texto considerações mais gerais sobre o conjunto de argumentos/referenciais encontrados nos diferentes textos destacando convergências, divergências e pontos silenciosos.

\section{A ambientalização da Educação Física no contexto da pesquisa acadêmica: o que dizem as produções científicas da área no Brasil}

A caracterização do "ambiental" é apresentada (com maior ou menor "densidade" teórica) nos textos por diferentes dimensões do acontecimento ambiental. Algumas características historicamente legitimadas pelos discursos ambientais (tanto no "sul"

5 Optou-se por não incluir na amostra os artigos com autoria ou co-autoria do autor do presente artigo. Essa escolha se justifica pela possibilidade de conflito de interesse que se apresentaria diante de uma análise de textos de própria autoria.

6 A pesquisa completa está publicada na Tese de Doutorado do autor (AUTOR, 2013). 
quanto no "norte"7) aparecem com maior frequência, como, por exemplo, a essencialidade da práxis na educação ambiental e o caráter interdisciplinar/multidisciplinar/ metadisciplinar/transversal da educação ambiental, citada por mais da metade dos artigos. Alguns artigos alicerçam a escolha pelas características apresentadas em metas/ objetivos definidos por documentos/eventos/programas internacionais, tais como a Década da Educação para o Desenvolvimento Sustentável (citada em dois artigos), a Política Nacional de Educação Ambiental (citada em três artigos) e o Tratado para as Sociedades Sustentáveis e Responsabilidade Global (citado em um artigo).

Também aparecem com frequência debates em torno dos termos desenvolvimento sustentável e sustentabilidade, com destaque para a diversidade de significados e complexidade desses conceitos. Destaca-se também o conceito paradoxal de desenvolvimento sustentável, considerando por um lado a ameaça às condições de vida representada pelo crescimento acelerado da economia global e por outro a exigência do desenvolvimento de comunidades humanas diante de condições de pobreza. Há também referência à reação de autores brasileiros (e "latinos" num contexto mais geral) contra o termo "educação para o desenvolvimento sustentável", levando-se em consideração o desenvolvimento de teorias associadas à educação ambiental crítica que, no contexto "latino", ganham novas "roupagens" sob outras denominações como, por exemplo, educação ambiental transformadora, educação ambiental popular e educação ambiental emancipatória.

Nesse contexto, três artigos fazem referência aos embates de força na constituição do "saber ambiental"/"racionalidade ambiental" e mais da metade dos artigos destacam a necessidade de criação de novos/diferentes valores ambientais ou a necessidade de criação de uma nova/diferente ética ambiental. A ideia da criação de novos/diferentes valores ambientais estaria alicerçada na concepção de uma "educação ambiental social", que teria por finalidade a construção de valores, conceitos, habilidades e atitudes que potencialmente possibilitariam a atuação responsável dos atores sociais (individuais e coletivos) no ambiente, sendo que esses novos/diferente valores estariam associados (juntando os conceitos apresentados no corpus de análise) à solidariedade, à cooperação, à igualdade de oportunidades/direitos e à interdependência. Já a necessidade de criação de uma nova/diferente ética ambiental estaria associada (novamente juntando os conceitos apresentados no corpus de análise) a uma visão de mundo sensibilizadora (associada à educação "estética"; dos sentidos/da sensibilidade); transformadora (em direção a relações integradas ser humano/ sociedade/meio ambiente); global; e coletiva/democrática/participativa.

7 Por "norte" se faz referência a um conjunto de países (Estados Unidos, Canadá, Inglaterra e outros do norte da Europa, e países com colonização dos países previamente citados geograficamente situados no hemisfério sul, como Austrália, Nova Zelândia e África do Sul) que historicamente desenvolvem linhas de pesquisa com raízes culturais bem distintas das que aqui serão chamadas de "latinas" ou do "sul" (compreendendo especialmente os países da América do Sul e do sul da Europa, como, por exemplo, Portugal, Espanha e Itália). Para uma leitura mais aprofundada sobre os enquadramentos críticos e pós- críticos dos discursos da educação ambiental em sua evolução no "norte" e no "sul" sugere-se a leitura de Payne e Rodrigues (2012). 
Ainda nesse sentido, três artigos criticam mais diretamente valores antropocêntricos e fragmentários, inclusive apontando esses valores como principais causadores da suposta crise cultural/civilizatória. Outros quatro artigos criticam mais diretamente a suposta simplicidade de atividades ecológicas/biologicistas/naturalistas, caracterizadas como "românticas" e ingênuas e com práticas focadas na sensibilização ambiental que possibilitam a legitimação de discursos reducionistas e com base em práticas comportamentalistas que, muitas vezes, estão na base da construção de práticas de greenwashing ${ }^{8}$. Em sintonia com tais críticas, boa parte dos artigos sugere mais diretamente o desenvolvimento de uma educação ambiental que seja "crítica", ou seja, que não seja alienada do mundo; que oponha a visão hegemônica; que critique os modelos autoritários, tecnocráticos e populistas que não consideram alternativas sociais baseadas em princípios ecológicos, éticos e justos com as gerações atuais e futuras; e que leve em consideração as preocupações com os segmentos mais excluídos da sociedade e com a naturalização de situações opressoras discriminatórias, buscando superar as injustiças ambientais e as desigualdades sociais. Em outras palavras, uma educação ambiental política, uma vez que reivindica e prepara cidadãos para exigir justiça social, cidadania e ética nas relações sociais e com a natureza.

Como unidade multiplicadora de impacto para a redução dos problemas ambientais, a escola desenvolveria papel fundamental. Nesse sentido, parte dos artigos destaca a importância da formação/ capacitação de docentes para a educação ambiental, afirmando que a inclusão de novos conteúdos em cursos de graduação para a formação de profissionais que trabalham com atividades na natureza possibilitaria um crescente qualitativo que contribuiria para a formação de cidadãos mais sensíveis e atentos às questões ambientais, assim como para a preparação de profissionais para atuar com a educação ambiental tanto na escola como na natureza (educação sobre/ para e na natureza). Para tanto, a criação do tema transversal "Meio Ambiente" aparece como alternativa entre os artigos. No entanto, parte dos artigos também afirma que as grades curriculares dos cursos de educação física não contemplam de forma efetiva o estudo sobre meio ambiente e que a política de educação ambiental não vem se mostrando suficiente para garantir a efetivação da educação ambiental nos currículos oficiais (inclusive na educação física). Assim, em parte responsabilizam a própria academia pelo "analfabetismo ambiental" contemporâneo.

Mais especificamente na área da educação física, a maioria dos artigos critica de alguma forma as abordagens caracterizadas como "tradicionais", destacando como principais características desse tipo de abordagem: (a) reducionismos fragmentários com bases materialistas que incluem algumas dicotomias clássicas da área, tais como mente-corpo, trabalho manual e intelectual

8 O termo "greenwash" (tradução literal seria algo como "lavagem verde") é usado na língua inglesa para se referir a uma estratégia de marketing "verde" maliciosamente/enganosamente usada para promover a percepção de que os objetivos e políticas de uma organização são ambientalmente corretas/amigáveis. 
e teoria-prática, sendo que a educação física deveria caminhar em direção à superação desta "tradição cartesiana" buscando, assim, caminhos que privilegiem a complexidade; (b) valorização do profissional técnico com foco na racionalidade formal ou instrumental, especialmente na educação física escolar; algumas terminologias parecem estar diretamente associadas a esse tipo de abordagem, tais como "treinamento de habilidades/aptidão física" e "aprendizagem motora"/"desenvolvimento motor"; (c) elitismos que contribuem para a discriminação e injustiça social, especialmente em práticas de educação física escolar que, em geral, são pautadas na exclusão pelos critérios de eficiência; (d) atividades competitivas/ esportivas. Curiosamente, apenas um artigo defende o desenvolvimento dos saberes "tradicionais", se esses estiverem associados ao desenvolvimento de novos/diferentes saberes que incluam o "ambiental".

Outra crítica presente na maior parte dos artigos faz referência à crescente expansão de atividades na natureza que por vezes se tornam mais um dos padrões de produção e consumo não sustentáveis, especialmente pela apropriação da natureza como símbolo distintivo do consumo diante da concepção de uma natureza "externa" em relação ao ser humano. Assim, os artigos em geral destacam a necessidade de uma educação que se contraponha a lógica consumista/cultura do consumo e seu papel na sustentação do sistema capitalista e que supere a concepção de natureza como forma de compensar os problemas "urbanos". Destacam ainda que inserções em práticas na natureza não significam necessariamente transformações de valores e ideologias, e enfatizam a irresponsabilidade de certas ações que se denominam sustentáveis, mas que na realidade funcionam no sentido oposto dessa expectativa.

Diante de tantas críticas aos modelos tradicionais de educação física e de abordagens reducionistas/fragmentárias para o desenvolvimento de atividades na natureza, os artigos apresentam diferentes alternativas: (a) uma compreensão de educação física como prática social/fenômeno cultural, com modelos de movimento que desenvolvam valores sociais e que estejam de acordo com a cultura local/regional; (b) valorização da brincadeira, da arte, do lúdico e das atividades de aventura na mediação das relações educação física-natureza; (c) uma educação física enraizada na atividade humana compreendida como "cultura corporal" (inclusive com formação de profissionais da "motricidade humana") ou "cultura de movimento"; (d) o desenvolvimento de um corpo/sujeito integral, ou seja, um "corpo" como intermédio de uma visão sistêmica. Aliás, esse último ponto foi destaque em grande parte dos artigos sendo apresentado a partir de diferentes propostas, tais como: (a) desenvolvimento de experiências do "corpomundo", compreendidas como expressões que ocorrem em contato corporal e direto com o mundo e com a natureza e que aguçam a percepção; (b) desenvolvimento da teoria da complexidade de Edgar Morin para sustentar a concepção do ser humano ecossistêmico; (c) desenvolvimento de fundamentos da fenomenologia para sustentar a ideia de que o ser humano é inseparável do mundo em que vive, especialmente enfatizando a relação entre corpo, cultura e natureza com foco na intencionalidade do movimento humano.

De maneira geral, a maioria dos artigos parece já ter incorporado conceitos que se aproximam dos discursos críticos/ 
pós-críticos de educação ambiental, assim como das críticas (pós)modernas aos paradigmas tradicionais da educação física. No entanto, a maior parte dos artigos também faz referência a uma série de dificuldades/ limitações encontradas na área da educação física para o desenvolvimento de abordagens "alternativas", inclusive considerando a inserção das questões ambientais. Entre elas destacam-se: (a) a falta de formação ou a formação acadêmica deficitária de professores da área para desenvolver a temática ambiental; (b) o conservadorismo de professores "antigos" e a consequente dificuldade para adoção/inserção de novas temáticas; (c) a resistência dos alunos a uma educação física que supere a cultura da prática pela prática; (d) a área de tensão e conflito entre os objetivos do esporte escolar e os interesses do sistema desportivo de alto rendimento; (e) a desvalorização da área no contexto escolar, resultando na carência de locais adequados para a prática de esportes na escola e na falta de apoio institucional de maneira geral. Sobre esse último ponto, há uma associação à preservação de áreas desportivas como atividade ambiental, considerando nesse contexto a importância do acesso às atividades físico-desportivas de qualidade e a ampliação do esporte e da educação física para que sejam acessíveis a todos.

\section{CONSIDERAÇÕES}

Apesar das recorrentes críticas às abordagens tradicionais da educação física e da manifestação da maior parte dos artigos em direção a abordagens "alternativas", é possível encontrar nos discursos conceitos e afirmações que mais se aproximam de abordagens "técnicas" com foco na racionalidade formal ou instrumental, assim como afirmações que se aproximam das criticadas abordagens preservacionistas/ naturalistas. Alguns discursos ainda enfatizam, por exemplo, a "educação motora" e o "desenvolvimento de habilidades" como papel fundamental da educação física; os "jogos motores" enquanto instrumentos da educação física; e o potencial dos esportes de aventura praticados na natureza no desenvolvimento de "capacidades físicas" e "habilidades motoras". Há também referências a potencial contribuição da educação física para dar subsídios à manutenção da higiene pessoal e de uma vida mais saudável (qualidade de vida), caracterizando, inclusive, essas atividades como "ambientais", uma clara evidência das "raízes vivas" da educação física na área da saúde.

Entre as afirmações que se aproximam de abordagens preservacionistas/ naturalistas, geralmente associadas à sensibilização como meio para transformação em direção a novos valores ambientais, a "fugas do cotidiano" ou ainda a abordagens compensatórias, destacam-se, por exemplo, afirmações que enfatizam o "momento oportuno" associado à educação física para a formação de "convicções ambientais" e de "proteção do meio ambiente", uma vez que suas atividades seriam realizadas predominantemente ao ar livre; a "eliminação do estresse" e da "sobrecarga intelectual" e a "manutenção da qualidade de vida" proporcionados pelo "contato direto com a natureza"; a realização das atividades de aventura que "sem dúvida" geram a compreensão da "importância da preservação do meio ambiente"; o "afastamento" de expressões céticas e individualistas que permeiam o cotidiano urbano a partir de "relações humanas mais diretas e intensas na natureza"; a capacidade das atividades 
de aventura de "levar o praticante a um nível de consciência" sobre diversas relações humanas, permitindo ainda um "distanciamento espaço-temporal das experiências cotidianas", inclusive as "sensoriais e motoras", supostamente ampliando as possibilidades de "autoconhecimento" e de "mudanças de hábito". Vale ainda um destaque para algumas das atividades ao ar livre que são sugeridas como meio para transformação em direção a novos valores ambientais, mas que, especialmente isoladas de um contexto ambiental mais amplo, também parecem se aproximar de abordagens preservacionistas/naturalistas, tais como excursões, acampamentos, recreação turística, mutirões de limpeza e plantação de mudas de plantas nativas.

De maneira geral, apesar de escassas e esparsas, evidenciando sua posição ainda bastante periférica, as propostas de inserção de questões ambientais na educação física apresentam um movimento particular que se constrói na intersecção do campo ambiental com o campo da educação física e de seus subcampos ou campos com os quais historicamente dialoga, como, por exemplo, esporte, lazer e turismo. Desse movimento originam-se novos/diferentes/"alternativos" olhares que podem gerar questionamentos/ transformações dos paradigmas dominantes os quais fazem parte da construção histórica desses campos, potencialmente gerando novos/diferentes embates de força e consequentes maneiras de pensar/fazer.

Analisados em conjunto os artigos parecem apresentar boa parte das principais características que compõem os discursos ambientais contemporâneos, inclusive em seus desenvolvimentos críticos e pós-críticos tanto no "norte" como no "sul". No entanto, quando analisados individualmente parece ainda faltar à maioria dos artigos uma "maturidade teórica" diante das "evoluções" dos discursos ambientais. Em outras palavras, apesar das "características ambientais" apresentadas estarem, em geral, de acordo com os discursos contemporâneos, parecem pouco avançar sobre o que já é conhecido, como se estivessem presentes nos artigos apenas para serem apresentadas aos acadêmicos da educação física, que, em teoria, pouco sabem da emergente sinergia entre sua área de atuação e a área ambiental. Não há dúvidas de que a divulgação dos discursos ambientais em veículos mais especificamente voltados para a área de educação física seja essencial para a legitimação deste encontro discursivo, especialmente considerando sua marginalidade como debate emergente. Há nesse sentido uma potencial oportunidade rara de construção discursiva "embrionária" no encontro entre dois campos distintos e que, levando em consideração a crescente urgência em promover investigações educacionais a partir de um imaginário "globalizante" (de forma mais cosmopolita e globalmente democrática), pode emergir como significativa contribuição para a contestação/(re)construção de paradigmas vigentes. No entanto, essa construção é "fragilizada" pela divulgação de discursos ingênuos e teoricamente "carentes", realidade que aumenta ainda mais a responsabilidade dos atores envolvidos na construção e na divulgação deste potencialmente conspícuo discurso emergente.

\section{REFERÊNCIAS}

AUTOR, 2013

BOURDIEU, P. Os usos sociais da ciência: por uma sociologia clínica do campo científico. São Paulo: Ed. UNESP, 2004. 
BURSZTYN, M. Meio ambiente e interdisciplinaridade: desafios ao mundo acadêmico. Desenvolvimento e Meio Ambiente, UFPR, n.10, p.67-76, jul./dez., 2004.

DOMINGUES, S. C.; KUNZ, E.; ARAÚJO, L. C. G. Educação ambiental e educação física: possibilidades para a formação de professores. Revista Brasileira de Ciências do Esporte, v.33, n.3, p.559-571, 2011.

FARIAS, C. R. O. A produção da política curricular nacional para a educação superior diante do acontecimento ambiental: problematizações e desafios. 2008. 215 p. Tese (Doutorado) - Programa de Pós-Graduação em Educação, Universidade Federal de São Carlos, São Carlos, 2008.

GUIMARÃES, S. S. M. e col. Educação física no ensino médio e as discussões sobre meio ambiente: um encontro necessário. Revista Brasileira de Ciências do Esporte, v.28, n.3, p.157172, 2007.

LEFF, E. Ambiente, interdisciplinariedad y currículum universitario: la educación superior en la perspectiva del desarrollo sustentable. In: ALBA, A. (Coord.) El currículum universitario: de cara al nuevo milenio. México: Centro de Estudios sobre la Universidad/UNAM/Plaza y Valdés Editores, 1997, p.205-211.

LEITE, D. M. T.; CAETANO, C. A. Educação física, esporte e lazer na natureza: preservação, modismo, apologia. Será tudo isso? Motrivivência, Ano XVI, n.22, p.137-143, Jun. 2004.

MARINHO; A.; INÁCIO, H. L. D. Educação física, meio ambiente e aventura: um percurso por vias instigantes. Revista Brasileira de Ciências do Esporte, v.28, n.3, p.55-70, 2007.
MENDES, M. I. B. S.; NÓBREGA, T. P. Cultura de movimento: reflexões a partir da relação entre corpo, natureza e cultura. Pensar a Prática, v.12, n.2, p.1-10, maio/ago. 2009.

MORAES, R. Uma tempestade de luz: a compreensão possibilitada pela análise textual discursiva. Ciência e Educação, v.9, n.2, p.191-211. 2003.

OSBORNE, R.; BATISTA, W. A. Educação

Física na década da Educação para o Desenvolvimento Sustentável. Motriz, v.16, n.1, p.28-36, jan./mar. 2010.

OSBORNE, R.; SILVA, C. A. F.; VOTRE, S. J. Educação física, esporte e desenvolvimento sustentável. Pensar a Prática, v.14, n.1, p.1-14, 2011 a.

PAYNE, P. G.; RODRIGUES, C. Environmentalizing the curriculum: a critical dialogue of south-north framings. Perspectiva, v.30, n.2, p.411-444, 2012. RODRIGUES, L. H.; DARIDO, S. C. Educação Física escolar e meio ambiente: reflexões e aplicações pedagógicas. Lecturas, Educación Física y Deportes, Ano 11, n.100, p.1-4, set. 2006.

SILVA, F. W.; SILVA, A. M.; INÁCIO, H. L. D. A Educação Física frente a temática ambiental: alguns elementos teóricometodológicos. Motrivivência, Ano XX, n.30, p.44-60, Jun. 2008.

SOUZA, M. S.; LARA, G. S. Prática pedagógica em educação física e a educação ambiental. Pensar a Prática, v.14, n.2, p.1-11, 2011.

TAVARES, F. J. P. A Educação Ambiental na formação de professores de Educação Física: uma emergente conexão. Lecturas, Educación Física y Deportes, Ano 9, n.61, p.1-5, Jun. 2003.

TAVARES, F. J. P.; LEVY, M. I. C. Implementação da educação ambiental 
na graduação de professores de educação física: uma reflexão. Revista Eletrônica do Mestrado em Educação Ambiental, p. 331-341, 2001.

VARGAS, J. E. N.; TAVARES, F. J. P. A

Educação Ambiental no contexto da
Educação Física Escolar. Lecturas, Educación Física y Deportes, Ano 10, n.69, p.1-5, fev. 2004.

\title{
ACADEMIC RESEARCH ON THE INSERTION OF THE ENVIRONMENTAL DIMENSION IN PHYSICAL EDUCATION IN BRAZIL
}

\begin{abstract}
The aim of the presented research targets the following question: considering the global dimension of the "environmental happening" and the tendency towards the environmentalization of different areas of knowledge, what developments stand out in the field of physical education in the context of academic research? The corpus of the research embraces proposals for the insertion of the environmental dimension in physical education in Brazil that were published in scientific journals. The corpus was analyzed using Textual Discursive Analysis and the results shine a light on trends and issues surrounding processes of environmentalization of physical education in Brazil today.
\end{abstract}

Key-words: Environment; Knowledge Management; Education.

Recebido em: fevereiro/2014 Aprovado em: maio/2014 